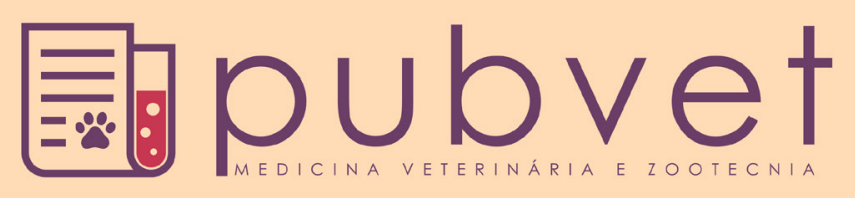

HTTP://DX.DOI.ORG/10.22256/PUBVET.V111N6.545-553

\title{
Bem-estar dos animais nos zoológicos e a bioética ambiental
}

\author{
Matheus Hernandes Leira ${ }^{1}$, Lucas Silva Reghim ${ }^{2}$, Luciane Tavares Cunha ${ }^{1}$, Letícia \\ Salomé Ortiz ${ }^{3}$, Cynthia de Oliveira Paiva ${ }^{3}$, Hortência Aparecida Botelho ${ }^{4}$, Lívia da Silva \\ Ciacci'$^{1}$; Mirian Silvia Braz ${ }^{5}$ Natália Pereira Dias ${ }^{3}$ \\ ${ }^{I}$ Professor e Pesquisador do Curso de Medicina Veterinária, Centro Universitário do Sul de Minas - UNIS-MG; *E-mail para \\ correspondência: matheus.hernandes@unis.edu.br \\ ${ }^{2}$ Discente do Curso de Medicina Veterinária - Iniciação Científica, Centro Universitário do Sul de Minas - UNIS-MG; \\ ${ }^{3}$ Discente do Curso de Medicina Veterinária, Centro Universitário do Sul de Minas - UNIS-MG \\ ${ }^{4}$ Mestre e doutoranda em Zootecnia, Universidade Federal de Goiás - UFG; \\ ${ }^{5}$ Mestre e doutorando em Medicina Veterinária, Universidade Federal de Lavras - UFLA-MG
}

RESUMO. Os zoológicos objetivam a conservação de espécies, o desenvolvimento e aperfeiçoamento profissional, a pesquisa científica, a educação ambiental e o lazer; porém a população busca os zoológicos principalmente para recreação e lazer, sendo que a maioria dos visitantes são famílias com crianças que pretendem apreciar a vida selvagem em companhia, ficando educação, fuga e introspecção menos importante, a oficialização dos zoológicos requer o cumprimento de exigências normatizadas pela legislação de cada país, a aquisição destes animais também precisa obedecer às normas rígidas de importação ou coleta em habitat natural, sendo que a fauna indígena não pode ser vendida nem trocada com outros estabelecimentos a não ser que seja fornecido permissão e aval dos órgãos competentes, condicionada à animais excedentes e devendo ter nascido em cativeiro, dentro das prioridades e obrigações morais dos zoológicos encontra-se a demanda de propiciar condições para que os animais exibam comportamentos naturais e automaticamente otimizem as condições de bem-estar animal.

Palavras Chaves: Animais de cativeiro, zoológico, bem-estar animal

\section{Animal welfare in zoos and environmental bioethics}

\begin{abstract}
The zoos are aimed at species conservation, professional development and improvement, scientific research, environmental education and leisure. However, the population searches for zoos mainly for recreation and recreation, and most visitors are families with children who want to enjoy wildlife in company, being less important education, escape and introspection, the officialization of zoos requires the fulfillment of requirements regulated by the legislation of each country, the acquisition of these animals must also obey the strict norms of importation or collection in natural habitat, and the indigenous fauna cannot be sold or exchanged with other establishments unless permission is given and endorsed by the competent organs, conditioned to surplus animals and Having been born in captivity, within the priorities and moral obligations of zoos lies the demand to provide conditions for the animals to exhibit natural behaviors and automatically optimize animal welfare conditions.
\end{abstract}

Keywords: Captive animals, zoo, animal welfare

\section{Bienestar de los animales en los zoológicos y la bioética ambiental}

RESUMEN. Los zoológicos tiene como objetivo la conservación de las especies, el desarrollo profesional, la investigación científica, la educación ambiental y recreacional, 
sin embargo, la gente busca los zoológicos principalmente para recreación y ocio. La mayoría de los visitantes son familias con niños que pretenden disfrutar de la vida silvestre acompañados, siendo educación, escape e introspección menos importante. Zoológicos oficiales requieren del cumplimiento de los requisitos establecidos por la legislación de cada país, la adquisición de estos animales también debe cumplir con los estrictos criterios de importación o recogida del hábitat natural, ya la fauna de indígenas no puede ser vendida o intercambiada con otros establecimientos, a menos que haya permiso y aprobación por parte de los órganos competentes, condicionada a los animales excedentes y que hayan nacido en cautiverio. Dentro de las prioridades y obligaciones morales de los zoológicos esta la demanda de proporcionar condiciones para que los animales exhiban comportamientos naturales y automáticamente optimicen las condiciones de bienestar animal.

Palabras clave: Animales en cautividad, zoológico, bienestar animal

\section{Introdução}

A cultura de manutenção de animais selvagens em zoológicos começou com os egípcios, os quais capturavam em suas viagens e batalhas pequenos gatos selvagens, babuínos e leões, e os mantinham em seus templos como símbolo de força e poder (Sanders and Feijó, 2007).

A prática de confinar animais existe desde civilizações antigas, como por exemplo, os egípcios que capturavam animais selvagens e os mantinham nos seus templos para representar força.

De acordo com Sanders and Feijó (2007), o primeiro zoológico do qual se tem registro, foi construído em 1752 em Viena, denominado Imperial Menagerie, no século XVIII em Paris, foi fundado o chamado "Jardin des Plants". Posteriormente, em 1826, foi fundado o Zoológico da sociedade de Londres com objetivo científico para estudo da zoologia. Nestes zoológicos, os recintos e as jaulas eram construídos para proporcionar aos visitantes o melhor ângulo de visão, e não para dar boas condições de vida aos animais, pois não havia uma preocupação com o bem-estar animal, somente em 1900 na Alemanha foi se preocupar com o bem-estar animal, inspirou outros países a seguir este modelo.

Os zoológicos foram criados basicamente com o propósito de expor espécies exóticas de animais à sociedade. No século XX houve uma mudança no enfoque da utilização dos zoológicos, que deixaram de ser meras coleções, passando a desenvolver atividades e funções voltadas para a conservação da fauna regional e global. Muitos estudos são desenvolvidos nos zoológicos modernos (Sanders and Feijó, 2007).

Animais em cativeiros possuem uma predisposição em desenvolver comportamentos anormais, o sucesso no cativeiro dependerá da capacidade que cada espécie apresenta em se adaptar a essas condições. E essa adaptação é uma pratica chamado enriquecimento ambiental (Newberry, 1995).

A prática de manter animais em cativeiro gera muitas polêmicas por privar o animal de expressar seu comportamento normal, porém, há benefícios quando tem objetivo de abrigar animais em reabilitação e extinção (Thomas et al., 2005).

\section{Legislação}

Trata-se de fato que a legislação é aberta à toda população ao movimento pelos direitos dos animais, todos tem direitos iguais uns aos outros. Apresentam-se leis que são destacadas as necessidades do bem-estar animal em um zoológico mostrando os direitos que todo animal tende de ter e seu funcionamento possibilitando diversos requisitos para o bem-estar das espécies fazendo um controle sobre sua saúde, segurança, manejo e conforto.

Pelo Artigo $1^{\circ}$ da Lei Federal 7173/83, que dispõe sobre o estabelecimento e funcionamento de jardins zoológicos, é considerado jardim zoológico qualquer coleção de animais silvestres mantidos vivos, em cativeiro ou em semiliberdade expostos à visitação pública (Sanders and Feijó, 2007). Os animais selvagens mantidos alojados recebem visitas na maior parte dos dias, e são expostos ao público como forma de entretenimento, quando ocorre um aumento de visitas os animais tendem a ficar agitados com a movimentação (Thomas et al., 2005).

A norma constitucional atribui um mínimo de direito ao animal, ou seja, o de não submeter seres sencientes a tratamentos cruéis, práticas que coloquem em risco a sua função ecológica ou ponham em risco a preservação de sua espécie, 
comando este assimilado pela Lei federal $\mathrm{n}$. 9.605/98, ao criminalizar a conduta daqueles que abusam, maltratam, ferem ou mutilam animais em seu artigo 32, são submetidos a situações desfavoráveis, ocasionando um stress, depressão e comportamentos anormais que as espécies tem devido ao confinamento (Sanders and Feijó, 2007).

O Artigo $9^{\circ}$, da mesma lei, dispõe que cada alojamento não poderá comportar número maior de exemplares do que aquele estabelecido e aprovado pela autoridade que concedeu o registro, outra ressalva: mas será este número de animais por alojamento, e o próprio alojamento, capaz de proporcionar um bem-estar para esses animais, os números de animais em cativeiros tendem estar crescendo cada vez mais, estes devem ter um espaço suficiente em cada instalação de acordo com cada espécie, pois devem proporcionar um ambiente seguro, arejado e confortável (Sanders and Feijó, 2007).

Animais que ficam alojados em um mesmo recinto correm riscos de machucar uns aos outros, em consequências de brigas por território ou acasalamento e podem também transmitir doenças aos outros animais (McPhee and Carlstead, 2010).

\section{Vantagens}

A relação humano-animal e a manutenção de animais em cativeiro datam de milênios, mas apenas recentemente, nas últimas três décadas, a preocupação com o bem-estar destes foi reconhecida como ciência. O que leva sempre os zoológicos e instituições preocuparem com o conforto e tratamento de animais, mantendo eles de forma segura, livre de caças predatórias, sempre mantendo espécies quase extintas ainda vivas (Saad et al., 2011).

A maioria dos zoológicos mudou seu objetivo que antes era somente para entretenimento, hoje estão voltados para a educação ambiental fazendo trabalhos com escolas e com a população, além de reabilitar os animais que chegam debilitados, que são apreendidos por maus tratos ou tráfico, entre outros. O bem-estar animal vem sendo a cada dia mais considerado, e o enriquecimento ambiental é a maneira mais adequada para uma melhor vida do animal cativo.

Infelizmente é considerável o número de espécies animais extintos, estes parques visam e ajudam na reprodução e introdução destas espécies na natureza. Outro foco são as pesquisas realizadas para avaliar e acompanhar os comportamentos, hábitos, saúde destes animais, o que ajuda também na preservação dos mesmos.

\section{Enriquecimento ambiental}

Mais de 85 milhões de animais que vivem em cativeiro sejam eles de produção, laboratório ou zoológico, apresentam algum tipo de estereotipia (transtorno) comportamental, porém, em uma meta análise, demonstrou a eficiência das técnicas de enriquecimento ambiental em mais de $90 \%$ dos trabalhos que objetivaram reduzir estes comportamentos (McPhee and Carlstead, 2010).

Ambientes enriquecidos podem contribuir para diversas atividades no zoológico, além de promover bem-estar aos animais cativos, o enriquecimento reduz o stress, prevenindo o surgimento de comportamentos anormais ou promovendo o tratamento (eliminação ou redução) de tais comportamentos na vida cativa. Animais criados e mantidos em ambientes enriquecidos raramente expressam comportamentos anormais e sim comportamentos similares aos expressados por seus semelhantes na natureza.

Os estímulos de enriquecimento podem aliviar também os efeitos do stress na fisiologia sexual, facilitando a reprodução; entretanto, só o fato do animal se reproduzir em cativeiro não indica que ele tenha um bom nível de bem-estar. Por serem criados em ambientes mais complexos, os animais podem apresentar diferenças significativas no comportamento de aprendizagem, ou seja, o ambiente enriquecido pode influenciar na habilidade do animal em se adaptar frente a novas situações. Isso contribuiu diretamente com programas de reintrodução de espécies, pois os animais apresentariam mais chances de sobreviver em seus ambientes naturais.

Segundo Thomas et al. (2005), o enriquecimento ambiental é um melhoramento no funcionamento biológico do animal, através do aumento no sucesso reprodutivo e melhora na saúde física, como resultado das modificações do seu ambiente.

De acordo com (McPhee and Carlstead, 2010) existem cinco tipos de EA - Enriquecimento Ambiental sendo os seguintes:

Físico: Está relacionado à estrutura física do recinto, consiste na introdução de aparatos que deixam o ambiente semelhante ao habitat natural da espécie; 
Sensorial: Consistem em estimular os cinco sentidos do animal: visual, auditivo, olfativo, tátil e gustativo, sons com vocalizações, odores de fezes e urina são exemplos deste tipo de EA;

Cognitivo: Objetiva estimular a capacidade mental do animal, e ocorre com dispositivos mecânicos a serem manipulados;

Social: Caracterizado pela interação intra (relações que podem ocorrer entre seres vivos da mesma espécie) ou interespecífica (relações entre espécies diferentes) que pode ser criada no ambiente. Os animais têm a oportunidade de interagir com outras espécies que naturalmente conviveriam na natureza ou com indivíduos de mesma espécie;

Alimentar: Promove um ambiente mais próximo do natural aos animais, podendo-se fazer variações na alimentação, de acordo com o hábito de cada espécie.

$O$ grande desafio de um programa de enriquecimento é, no entanto, proporcionar estímulos e opções de escolhas enquanto minimizam potenciais riscos à saúde animal. $\mathrm{O}$ enriquecimento pode ser alcançado por inúmeras modificações físicas e sociais no ambiente do animal (McPhee and Carlstead, 2010).

\section{Reprodução}

De acordo com o Ministério do Meio Ambiente, o processo de extinção está relacionado ao desaparecimento de espécies ou grupos de espécies em um determinado ambiente ou ecossistema. Semelhante ao surgimento de novas espécies, a extinção é um evento natural: espécies surgem por meio de eventos de especiação (longo isolamento geográfico, seguido de diferenciação genética) e desaparecem devido a eventos de extinção (catástrofes naturais, surgimento de competidores mais eficientes). Diz ainda que, ao longo do tempo, porém, o homem vem acelerando muito a taxa de extinção de espécies, a ponto de ter-se tornado, atualmente, o principal agente do processo de extinção. Em parte, essa situação deve-se ao mau uso dos recursos naturais, o que tem provocado um novo ciclo de extinção de espécies, agora sem precedentes na história geológica da terra.

Existem vários fatores que contribuem para a extinção de espécies, como a degeneração de ambientes naturais, extrativismo desordenado, poluição, desmatamento, queimadas florestais, formação de lagos para hidrelétricas, abertura de pastos para agricultura ou pastagem, entre outras causas, por último, e não menos importante, a introdução de espécies exóticas, que por serem competitivas e favorecidas pela ausência de predadores, acabam por dominar nichos ecológicos ocupados por espécies nativas. Afinal o que são espécies ameaçadas de extinção? São aquelas, em que as populações e habitat estão desaparecendo rapidamente, para que isso não aconteça, existem maneiras de proteger estes animais.

Animais de zoológicos são adquiridos por permutas com outras instituições, como por exemplo, animais ameaçados de extinção são resgatados pelo IBAMA, e com isso há maneiras de reprodução estudadas pelos biólogos e veterinários, que pretendem conservar espécies ameaçadas e reintroduzi-las na natureza. As técnicas de reprodução assistida incluem inseminação artificial, transferência de embriões e fertilização in vitro. Para que haja sucesso, é necessário que as etapas sejam feitas de forma correta e o menos estressante possível, visando sempre o bem-estar do animal.

\section{Reabilitação e pesquisas}

É auto o índice de animais atropelados que é levado para zoológicos com o intuito de receberem os cuidados necessários e assim se reabilitarem e serem devolvidos a natureza. Devido à expansão das cidades para as áreas habitadas pelos animais, estes estão se deslocando para áreas urbanas onde causam transtornos à população e podem também se ferir.

É de grande importância o papel que estas instituições exercem sobre o aspecto da introdução do animal no seu habitat. Constata-se que infelizmente muitos não conseguem adaptar a vida em liberdade por consequências dos danos sofridos.

Para obter sucesso na reabilitação devem ser considerados alguns passos, quando recolhidos os animais passam por uma triagem onde são feitos exames para avaliar as condições de saúde que se encontram. $O$ dia a dia da recuperação é acompanhado de perto, e este acompanhamento continua mesmo após a soltura, com o objetivo de avaliar a adaptação do animal, e também contribuir nas pesquisas que são feitas analisando seus passos como, por exemplo, a alimentação, a reprodução, a locomoção, o contato com outros animais da mesma espécie, seus hábitos em geral. 
Outro aspecto estudado por pesquisas é o comportamento animal, onde busca entender e levar em consideração aspectos que melhorem a qualidade de vida do animal no cativeiro e também a preservação do mesmo quando em liberdade. Métodos para reprodução assistida estão sendo testados para ajudar a combater a extinção de espécies. Patologias e zoonoses são pontos extremamente importantes inclusos nas pesquisas tanto para prevenção quanto para combate.

\section{Educação ambiental}

Atualmente, não se pode manter um zoológico apenas para abrigar animais. Na programação de muitos zoológicos a Educação Ambiental já está incluída, sendo uma das formas mais eficientes para transformar a mentalidade antiga de ver os animais apenas como bonecos enjaulados (McPhee and Carlstead, 2010).

O desenvolvimento da consciência ambiental, a nível internacional, pode ser traçado ao longo das duas últimas décadas, com base em uma série de eventos, como as Conferências de Estocolmo e a de Tibilisi que originaram as primeiras manifestações dentro da Educação Ambiental (Broom and Johnson, 1993).

De acordo com Thomas et al. (2005), "A Educação Ambiental que um zoológico pode oferecer combina conceitos de diferentes áreas, tais como zoologia, ecologia, botânica, fisiologia, etc.”. Isso faz com que uma atividade de campo em um zoológico seja uma boa oportunidade para despertar nos alunos o interesse para compreender diversas matérias em conjunto.

Devido aos resultados positivos que este trabalho traz para a sociedade, as escolas procuram cada dia mais os zoológicos para realização de aulas dinâmicas, onde os alunos podem ter contato com os animais silvestres, conhecer sobre seus hábitos naturais e entender a importância da preservação.

Segundo Broom and Johnson (1993), a identificação adequada dos animais é uma das exigências fundamentais de um zoológico, porém, felizmente, muitos deles têm levado sua mensagem educativa muito além de placas de identificação.

\section{Desvantagens}

Se tratando de animais mantidos em cativeiro, são abordados diversos aspectos negativos, a visão geral é que os animais são aprisionados em lugares inadequados sem suportes suficientes, por mera exibição e lucratividade, muitos animais mantidos em cativeiro são obtidos de forma ilegal e são maltratados, acarretando em danos comportamentais, físicos e mentais.

\section{Tráfico de animais}

O conceito de tráfico é "COMÉRCIO ILEGAL". Tráfico de Animais Silvestres significa a captura ilegal de animais na natureza para venda, a América do Sul é um dos grandes alvos por sua rica biodiversidade, da fauna e flora silvestre (Thomas et al., 2005).

Segundo o relatório, publicado em 2001 pela Rede Nacional de Combate ao Tráfico de Animais Silvestres - RENCTAS, o Brasil participa com cerca de $5 \%$ a $15 \%$ do total mundial. Esse mercado é o que movimenta expressiva renda por todo o mundo, além de ocasionar óbitos, sofrimento animal devido à captura, manutenção e transporte em condições indevidas e desequilíbrios ambientais.

Dentre os principais tipos de tráfico estão a coleta de animais para colecionadores particulares e zoológicos, este talvez seja o mais cruel, pois prioriza as espécies mais ameaçadas; animais para fins científicos, que servem como base para pesquisa e produção de medicamentos; animais para pet shop, e produtos de fauna, como couro, peles, penas, garras, entre outros que são muito utilizados para fabricar adornos e artesanatos, cujas espécies envolvidas variam de acordo com os costumes e a moda (McPhee and Carlstead, 2010).

Uma das piores realidades que se enfrenta são as condições de tratamento dos animais. Apesar de existirem técnicas de manejo e transporte adequadas às espécies, os animais são confinados em pouco espaço, sem água e alimento, onde se estressam, se mutilam e se matam. Além da ingestão de bebidas alcoólicas, muitas vezes os animais são submetidos a práticas cruéis que visam a amortecer suas reações e fazê-los parecer mais mansos ao comprador e chamar menos atenção da fiscalização (Broom and Johnson, 1993).

Dentre os impactos mais significativos gerados pelo tráfico de animais destaca-se a redução da abundância de determinadas populações, visto que a captura excessiva é a segunda principal causa da redução populacional de várias espécies, perdendo apenas para a degradação e a redução dos habitats provocadas pelo desmatamento (McPhee and 
Carlstead, 2010). Com a remoção de algumas dessas populações, o ecossistema sofrerá modificações, alterando toda uma comunidade e suas relações com o meio em que vive.

$\mathrm{O}$ tráfico ilegal reflete negativamente em termos sanitários, econômicos e ecológicos. Sanitários por que quando os animais são comercializados ilegalmente, não passam por qualquer controle sanitário, podendo transmitir doenças graves que vão desde a febre amarela, raiva até mesmo tuberculose e doenças desconhecidas (McPhee and Carlstead, 2010).

Além disso, importante ressaltar que, a atitude da sociedade perante toda essa irregularidade, é a de impunidade, de forma que é comum a permanência de feiras, lojas irregulares e criadouros clandestinos, que tão somente encoraja o comércio ilegal (Thomas et al., 2005).

A Legislação Brasileira impossibilita a remoção um animal de seu habitat e comercializar, mas como possui uma grande extensão, é muito difícil a fiscalização. O comércio ilegal está relacionado a problemas culturais, econômicos, por status e satisfação pessoal. O transporte é realizado, muitas vezes em lugares inacessíveis ou pouco monitorado, conforme McPhee and Carlstead (2010) dá desde carros, roupas, malas, até containers, que são muito utilizados por não serem frequentemente checados, devido ao grande movimento nos principais portos do país. O uso de documentos legais para encobrir produtos ilegais também é frequente, assim como a transformação dos animais para parecerem outros.

As aves são um dos animais mais encontrados no comércio ilegal, tanto o animal vivo, como mortos, para a retirada de suas penas, couros, ovos e outras partes. Geralmente, as aves mais desejadas para o tráfico no Brasil são aves cantoras ou aquelas que podem se tornar animais de estimação, o que lhes confere alto preço de mercado. Os peixes de aquário também são muito populares, inclusive nos Estados Unidos ( $\underline{\text { McPhee }}$ and Carlstead, 2010).

Outra grande demanda é a pele de répteis como crocodilos, cobras e lagartos, que são muito utilizadas para diversos artigos: sapatos, bolsas, roupas, malas, pulseiras de relógio, cintos e outros, sem falar da procura para animais de estimação exótica (Broom, 1991).

\section{Recintos inadequados}

Animais em cativeiro vivem em ambientes denominados recintos, onde se deve ao máximo ter características como o habitat natural de cada espécie, trazendo o maior conforto e bem-estar possível. Mas na prática não é o que ocorre, na maioria das vezes nos deparamos com animais enjaulados em pequenos espaços, onde não conseguem se locomover adequadamente, não podem se exercitar.

Locais sem a menor estrutura para mantê-los, este modo de vida traz consequências físicas e psicológicas graves podendo acarretar até mesmo na morte dos animais cativos. Um fator normalmente associado ao confinamento é a ausência das possibilidades para explorar, investigar e interagir socialmente. Estes animais apresentam déficits exploratórios e desenvolvem o medo, e também uma predisposição ao estresse (Broom and Johnson, 1993).

De acordo com McPhee and Carlstead (2010) a exploração possui caráter recompensador para o animal, e a ausência de oportunidade exploratória pode acarretar em estresse podendo levar a psicopatologias e comportamentos anormais, o que prejudica sensivelmente o bem-estar do indivíduo.

Recintos inadequados impedem os animais de expressar seu comportamento natural, o que é um dos aspectos abordados no bem-estar animal. Em vida-livre os animais são expostos a um ambiente desafiador, em constante mudança, onde exigências físicas e cognitivas são continuamente impostas, como: evitar predadores, encontrar e obter alimento, percorrer terrenos de diferentes níveis, defender o território de outros animais e/ou co-específicos, socializar, acasalar, entre outros estímulos variados. No entanto o contraste com o ambiente cativo é alto: espaço restrito, falta de complexidade, rotinas de manejo permanentes (como alimentação facilitada) e o contato com humanos. Todos estes fatores tornam o ambiente altamente previsível e sem opções para o controle das variáveis fundamentais para o seu conforto e bem-estar (McPhee and Carlstead, 2010).

Uma entidade que visa melhorar as condições dos animais mantidos em cativeiro no mundo, chamada Wild Welfare, postou uma avaliação em relação aos zoológicos brasileiros em sua página, um trecho desta avaliação diz o seguinte: "Recintos desatualizados", recursos limitados, e a falta de uma boa legislação federal e estadual, e um nível elevado de animais resgatados que estão sendo tomadas pelos zoológicos brasileiros a cada ano contribui para as precárias instalações e um 
mal-estar para centenas de animais dentro dos jardins zoológicos.

Muitos animais em coleções brasileiras vêm de apreensões do tráfico ilegal, bem como o número de animais apreendidos certamente representa apenas uma pequena parte do número real de animais ilegalmente capturados na natureza.

Em aquários animais de grande porte que livremente migrariam pelo oceano, vivem em piscinas ou tanques impedindo a locomoção e contato com os outros da mesma espécie.

O documentário Black Fish (2013) comoveu o mundo coma história da baleia Tilikum e com os relatos de ex-treinadores sobre as más condições e maus tratos aos animais no SeaWorld, um parque aquático em Orlando que recebe milhares de visitas.

Entre as especificações, estão as dimensões que uma jaula deve ter para certa espécie, quantos animais podem ficar dentro de cada uma delas, que tipo de alimentação eles devem receber, quais temperatura e arquitetura os espaços requerem, como será monitorada a qualidade da água e com quantos biólogos e Médicos veterinários cada unidade de zoológico ou aquário deve contar (Broom and Johnson, 1993).

Uma medida que vem sido tomada para melhorar a situação dos animais, e integrá-los com o ambiente que seria o seu habitat natural, e os adaptando para exercer as funções que teriam vivendo livremente, é o enriquecimento ambiental, prática que vem sido adotada para proporcionar uma vida melhor aos animais mantidos em cativeiro.

\section{Alimentação e nutrição}

É um grande desafio alimentar de maneira correta os animais mantidos em cativeiro, para uma boa alimentação devem-se considerar os alimentos que o animal está habituado a ingerir quando está na natureza e os nutrientes que o alimento fornece ao animal.

Existem fatores que devem ser levados em consideração ao escolher a dieta adequada, como por exemplo, crescimento, gestação, postura de ovos, lactação, doença, convalescença, a época do ano, o tipo de alojamento e outros.

Uma má alimentação ou uma dieta inadequada traz prejuízos a saúde do animal gerando doenças pela falta de nutrição, consequências físicas como a obesidade ou perda de peso e até mesmo a morte.
Existe uma deficiência na área de estudos em nutrição de animais silvestres, pois as pesquisas sempre foram concentradas em animais domésticos e buscando produção.

Com as mudanças nas necessidades de mercado, de se ter uma opção silvestre no cardápio, estas pesquisas têm se voltado para as espécies com interesse zootécnico.

O maior número de trabalhos com a alimentação de animais silvestres está nos hábitos alimentares. Apenas a partir da década de 80, os estudos na área de exigências nutricionais de animais silvestres se tornaram mais significativos (Saad et al., 2011). Animais em cativeiro gastam menos energia que em seu habitat natural, este aspecto também deve ser analisado para adequar a alimentação.

Segundo McPhee and Carlstead (2010) a presença de taninos e compostos polifenólicos é importante na dieta de animais silvestres, já que na natureza, participam consideravelmente da dieta desses animais e em cativeiro. Os taninos são conhecidos de longa data por apresentarem características como: reduzir a digestibilidade aparente da dieta, toxicidade (fator antinutricional) e reduzir a palatabilidade de forrageiras. No entanto, recentemente, o potencial antioxidante e cardioprotetor dos taninos e compostos polifenólicos tem sido enfatizado na nutrição humana.

Apesar de avisos e orientações sobre as dietas de cada animal, os visitantes são imprudentes e os alimenta inadequadamente o que traz malefícios para a saúde.

\section{Consequências físicas e comportamentais}

O estresse deve ser entendido como um processo fisiológico, neuro-hormonal, pelo qual passam os seres vivos para enfrentar uma mudança ambiental, na tentativa de se adaptar às novas condições e, assim, manter a sua homeostasia. Trata-se de um estado manifestado por um conjunto de respostas específicas do organismo e desencadeado por diferentes tipos de agentes, que são denominados estressores ( $\underline{\mathrm{Saad} \text { et }}$ al., 2011).

Classicamente, um agente estressor é aquele que possui a capacidade para alterar a homeostasia, provocando a ativação do eixo hipotalâmico-hipofisário-adrenal. Como exemplos de agentes estressores, pode-se citar fome, dor, calor/frio, ansiedade, medo, entre 
outros fatores. As respostas diante de um agente estressor se manifestam em três fases de acordo com o tempo, o primeiro estágio é chamado de reação de alarme, é o momento que o animal depara com o estressor, ocorre uma imobilização do organismo na tentativa de adaptação, o Segundo estágio conhecido como adaptação ou resistência, ocorre quando o estímulo continua mantido e o último estágio é o de exaustão, dá-se através do contínuo estímulo estressante ao ponto que o animal não possua mais capacidade de se adaptar, sem retorno a homeostasia.

De acordo com Broom and Johnson (1993) o animal busca habituar-se à presença do estressor, entrando num estado no qual a resposta a este se torna diminuída e pode ocorrer até mesmo diante da perspectiva do estímulo (Broom and Molento, 2004).

Outra classificação importante do estresse é relacionada à sua natureza, forma de manifestação e consequências desencadeadas. Assim, o estresse pode ser chamado de eustresse (quando se tratar de um evento positivo, ou seja, do estresse necessário à sobrevivência do indivíduo frente a uma adversidade) ou distresse (quando o estresse desencadeado acabar sendo prejudicial ao organismo).

O eustresse normalmente se relaciona à fase de alarme do estresse, quando há retorno à homeostasia, e o distresse às duas últimas fases (resistência e exaustão), nas quais já podem começar a ocorrer danos orgânicos (Saad et al., 2011).

Broom and Molento (2004) afirmam que o estímulo estressor pode desencadear diferentes respostas em diferentes organismos e dependendo da forma com que o indivíduo responde a este estímulo, pode se transformar num estresse positivo ou negativo. Ainda de acordo com Newberry (1995) as principais causas de estresse para os animais selvagens em cativeiro podem ser agrupadas em algumas categorias:

Estressores somáticos - sons, imagens e odores estranhos, manipulação, mudança de espaço físico (de ambiente), calor e frios excessivos e efeitos de fármacos e agentes químicos.

Estressores psicológicos - sentimentos de apreensão, que podem intensificar-se para ansiedade, medo e terror, na sua forma mais severa.

Estressores comportamentais - disputas territoriais ou hierárquicas, superpopulação, condições não familiares de ambiente, mudanças no ritmo biológico, falta de contato social, de privacidade, de alimentos e de estímulos naturais e problemas induzidos pelo próprio homem, como o alojamento próximo de espécies antagônicas (por exemplo, um predador próximo a uma presa).

Estressores mistos - má-nutrição, intoxicações, ação de agentes infecciosos e parasitários, queimaduras, cirurgias, administração de fármacos, imobilização química e física e confinamento.

A alteração dos padrões comportamentais de animais em cativeiro é indício de estresse. De acordo com (Saad et al., 2011), esses desvios podem ser agrupados nas seguintes categorias:

Estereotipias - são caracterizadas pela repetição de movimentos, aparentemente sem objetivo, como, por exemplo, balançar o corpo para os lados ou para frente e para trás, e andar de um lado para o outro, entre outras manifestações.

Estes comportamentos podem estar relacionados a uma má-adaptação atual ou referirse a alterações causadas por traumas do passado. Alguns pesquisadores acreditam que a estereotipia é um evento positivo porque melhora a condição física e diminui as emoções negativas dos animais. Outros afirmam que o comportamento estereotipado pode acarretar um gasto muito grande de tempo e energia por parte dos indivíduos.

Comportamentos autodestrutivos são caracterizados por uma agressividade contra o próprio corpo, relacionam-se à automutilação e arrancamento de penas ou pelos, mordedura, lambedura, ingestão de fezes, de madeira, de terra, de excesso de alimentos e de água, dentre outros.

Agressividade dirigida a outros animais do grupo ou hiperagressividade que inclui $o$ canibalismo, o infanticídio (matança de recémnascidos) e o feticídio (indução de aborto, provocando morte ao feto), que ocorrem em algumas situações e, principalmente, nas condições de estresse social.

Falhas em funções comportamentais: inadequação do comportamento sexual (cio silencioso, impotência nos machos), maternal (rejeição ou canibalismo dos neonatos) e nos movimentos básicos, como dificuldade para deitar-se, levantar-se ou locomover-se, reatividade anormal: apatia, inatividade prolongada, hiperatividade e histeria. 
Comportamentos no vácuo ou comportamentos atípicos, construção de ninhos com materiais impróprios, atividade sexual dirigida a estímulos inadequados, dentre outros.

Conforme Saad et al. (2011) deve-se, portanto, tentar satisfazer da melhor forma possível as necessidades básicas dos animais, adotando-se alternativas para a melhoria do seu bem-estar, como, por exemplo, a promoção do condicionamento dos animais e a utilização de práticas como o enriquecimento ambiental.

\section{Conclusão}

$\mathrm{O}$ enriquecimento ambiental envolve a estrutura do recinto que melhora as condições físicas do ambiente, e a parte cognitiva que estimula a capacidade mental e mecânica do animal, a parte alimentar promove um ambiente próximo do natural com uma dieta inspirada na sua alimentação e a parte social visa não deixar o animal solitário, sempre buscando parear os animais nos recintos.

O comércio de animais traficados obtém lucro a partir de vendas de animais exóticos, destinados a diferentes locais, como por exemplo, centros de pesquisa, zoológicos, parques, circos e pessoas que simplesmente querem possuir por pura vaidade.

A existência dos zoológicos se configura como um problema ético contemporâneo caracterizado por questões complexas, plurais e de interesse internacional. A impossibilidade de resolução desses problemas apenas utilizando-se de princípios morais e legais locais de cada cultura, bem como os argumentos favoráveis e contrários à existência dessa instituição por múltiplos sujeitos/atores demanda a intervenção da bioética ambiental.

\section{Agradecimentos}

Centro Universitário do sul de Minas - UNISMG e a FAPEMIG

\section{Referências Bibliográficas}

Broom, D. M. 1991. Assessing welfare and suffering. Behavioural Processes, 25, 117-123.

Broom, D. M. \& Johnson, K. G. 1993. Stress and animal welfare. Springer Science \& Business Media, London.

Broom, D. M. \& Molento, C. F. M. 2004. Animal welfare: concept and related issues-review. Archives of Veterinary Science, 9, 1-11.

McPhee, M. E. \& Carlstead, K. 2010. The importance of maintaining natural behaviors in captive mammals. University of Chicago Press, Chicago.

Newberry, R. C. 1995. Environmental enrichment: increasing the biological relevance of captive environments. Applied Animal Behaviour Science, 44, 229-243.

Saad, C. E. P., Saad, F. M. d. O. B. \& França, J. 2011. Bem-estar em animais de zoológicos. Revista Brasileira Biociências, 40, 38-43.

Sanders, A. \& Feijó, A. G. S. 2007. Uma reflexão sobre animais selvagens cativos em zoológicos na sociedade atual. Congresso Internacional Transdiciplinar Ambiente e Direito. PUC, Porto Alegre, Brasil.

Thomas, P., Balme, G. \& Hunter, L. 2005. Enriching zoo felids: Applyng lessons learned to enchance field conservation techniques. Seventh International Conference On Environmental Enrichment. New York.

Article History:

Received 24 February 2017

Accepted 3 April 2017

Available on line 12 May 2017

License information: This is an open-access article distributed under the terms of the Creative Commons Attribution License 4.0, which permits unrestricted use, distribution, and reproduction in any medium, provided the original work is properly cited. 